\title{
The transformative potential of the Sustainable Development Goals (SDGs)
}

\author{
Casey Stevens ${ }^{1} \cdot$ Norichika Kanie $^{2}$
}

Published online: 13 April 2016

(C) Springer Science+Business Media Dordrecht 2016

How can global governance shape a transformation toward sustainability? How can a transformation toward sustainability shape new forms and strategies on global governance? These questions grow increasingly important as the human impact on the environment increasingly exceeds the planetary boundaries (Rockström et al. 2009; Steffen and Smith 2013; Steffen et al. 2015). In addition, the prevailing approach to sustainability will only achieve sustainable futures for some, which would not be sustainable at all. In the post1992 era, roadblock after roadblock for global governance on sustainability was confronted and increased skepticism became warranted. In this context, the Rio +20 Conference in 2012 was seen as a conference with little substantive purpose (Andresen and Underdal 2012) and interest grew in efforts that "tipped toward" sustainability (Westley et al. 2011) rather than hard law-induced transformations. Global governance was seen to have the wrong processes and wrong ideas, animated by zero-sum interstate negotiations and a prioritization of the liberal international economic order over any alternatives. If we approached the question from a traditional effectiveness or influence perspective (Bernstein and Cashore 2012), such skepticism is understandable. Formal rules of the environment gave way to less legalistic approaches to sustainability in a muddled institutional context. Specifically, the Rio +20 process produced nothing in the realm of hard law, and the small-scale efforts appear scattered haphazardly without a core to organize global action. An alternative approach though would highlight that such outcomes have potential impacts primarily in changing global governance practices, defined as the techniques actors use to make sense of the world (Best 2014). Such an approach would be critical of the

Casey Stevens

casey.c.stevens@gmail.com

Norichika Kanie

kanie@sfc.keio.ac.jp

1 Clark University, Worcester, MA 01610, USA

2 Keio University, 5322 Endo, Fujisawa, Kanagawa 252-0882, Japan 
failures of global governance but would not ignore the "seeds of substantive transformation" that exist in efforts like the Rio+20 outcomes (Pattberg and Mert 2013, p. 306).

The idea for the Sustainable Development Goals (SDGs) emerged during the process leading to the Rio+20 United Nations Conference on Sustainable Development. The Rio+20 Conference in 2012, in its outcome document The Future We Want, agreed to a process unlike many others to negotiate and develop consensus on the SDGs (UN General Assembly 2012). Negotiations to form the SDGs occurred primarily through the Open Working Group in the United Nations (UN) with concurrent, but not always synchronized, discussions regarding financing and the larger post-2015 development agenda. In addition, consultation with a wide variety of actors took place in the $\mathrm{UN}$, at regional and national levels, as well as through a web-based platform reaching a wider audience. The result of these discussions is a set of 17 SDGs with 169 targets. While many of these goals look quite similar to the eight Millennium Development Goals, much of the content expands on those in a variety of different ways. Environmental dimensions, the interconnection between different problems, interrelated aspects of poverty and marginalization, and others are much more pronounced in the SDGs than they were in earlier efforts.

While the SDGs do represent a different approach, their potential for transforming the dominant governance approaches to sustainability remains an open question. Global collective action does not end when decisions are reached, but these decisions introduce new practices in a complex political process that can bring in new actors, new ideas, and new action for sustainability. To unpack the practices of global governance that can contribute to a transformation toward sustainability, it is crucial to analyze the decision-making processes and the transformative ideas that are captured in those decisions. While neither processes nor ideas are a guarantee of transformation, they help to understand the potential impacts.

The 2030 Agenda for Sustainable Development and the SDGs offer a potential to transform the dominant approaches to economic, social, and environmental challenges. In many ways it shares similarities with the earlier UN Decades of Development and the most recent Millennium Development Goal era (2000-2015); however, there are some key differences in this agenda. First, although the earlier efforts often took a narrow view on economic development, the SDGs aim to create an integrative agenda that includes environmental sustainability and social concerns with the poverty eradication agenda (Griggs et al. 2013). Second, the preparation of the SDGs was undertaken through a lengthy, open, and transparent process with many actors involved in the various levels of discussions, in contrast to the earlier efforts involving only narrow groups of internal UN actors. The ideas that informed the discussions and the processes of forming the SDGs thus were different from earlier efforts. The very title of the agenda, "Transforming our world: the 2030 Agenda for Sustainable Development," brings sustainable development in as an integral part of the governance effort.

This Special Feature on "Making the SDGs Succeed" suggests that the SDGs are an opportunity to permanently transform the nature of development and make environmental and social sustainability a defining characteristic of economic activity. The articles explore how these goals were created and discusses the limitations on the resulting agenda. The formation process of the SDGs was unique when compared with other global governance efforts (as will be explored more in Chasek and Wagner, this issue) and can help us understand the transformative impact of key actors like leaders in international negotiations, the inclusion of civil society, and efforts to work around the negotiating blocks prominent on most global environmental governance decisions. The aims of the SDGs in the Rio +20 outcome were quite significant aiming to be aspirational, universal, inclusive, 
integrated, action-oriented, transparent, etc. While each of these may simply be a buzzword that has little impact on action, some aspects of these ideas can become important practiceguiding cores of discussion. Understanding what these ideas could entail in global sustainability governance and what they are likely to mean in early implementation is crucial in understanding the transformational potential of the SDGs. The practice lens adopted by the articles in this Special Feature adds specific insights crucial to understanding the current era of global environmental governance more widely.

The formation of the SDGs yields significant insights into global environmental governance more generally and key issues of institutional politics and the engagement of civil society. In contrast to other processes of intergovernmental rule negotiation in global environmental politics where consensus decision making grew fatigued in the post-Rio (1992) era, Chasek and Wagner argue that key aspects of the SDGs formation process broke the mold. The use of so-called troikas broke down cemented negotiating blocks, the lengthy stocktaking process helped develop mutual trust between participants, and continuous monitoring and control of the text by the co-chairs themselves served to create a different negotiating environment. What, in the words of Chasek and Wagner, "could not have been imagined 3 years earlier" thus came into existence through a different negotiating process. In addition to state-led negotiations at the UN Headquarters, a wider set of processes aiming to include civil society in the discussion occurred. These processes include: A Million Voices: The World We Want; Delivering on the Post-2015 Agenda: Opportunities at the National and Local Level; and MY World Survey, to name a few. Gellers' article in this issue explores the MY World Survey and e-discussions on environmental sustainability to explore the potential and pitfalls of "crowdsourcing" global environmental governance. While different technological tools were used to solicit input (including paper ballots, SMS text messages, and Web site responses), a number of distorting influences restrained crowdsourcing in the SDGs' process. Gellers argues that such civil society "crowdsourcing" efforts could be more significant tools in global environmental governance if it takes into account the different abilities for people to access and use technology (the "digital divide") and which kinds of social actors are drawn to different modes of input.

While there are important aspects regarding interstate negotiations and civil society participation in the formation of the SDGs, the ideas that resonate within those 17 goals are also important. The Rio+20 outcome document asked for the SDGs to be transformative. The influence of the SDGs may be most significant in its ability to change the idea of development from a purely economic approach, to one that includes a host of other issues. Gupta and Vegelin push the SDGs to explore how they can move beyond the "continuous economic growth" model. Using the concept of inclusive development, which emphasizes social, environmental, and relational dimensions of inclusiveness, Gupta and Vegelin argue that although the SDGs emphasize social and environmental aspects, they do not question the growth-oriented development model. Furthermore, although the SDG text demonstrates a rhetorical commitment to inclusiveness with over 40 references to inclusion and includes a target to address inequality, there is relatively little emphasis on how power differentials that lie at the heart of inequality can be addressed. This may be the limit of the agreement made through intergovernmental negotiations, as the representatives are based in established institutions. If genuine transformation lies beyond this limit, issue framing may in turn pave the way. The final article by Boas, Biermann, and Kanie furthers this critical attention of the substance by exploring how the efforts within the SDGs can move beyond the narrow silos of action which define most development efforts and instead toward a focus on the nexus of connections between issues. For example, rather than viewing water, 
energy, and food issues as separate, a nexus approach looks at them as interconnected problems that necessitate interconnected governance responses. Boas et al. demonstrate that while many of the 17 SDGs remain largely sectoral in their approach, there are opportunities in the post-2015 era to institutionalize a nexus approach. These would require that the nexus approach gets a prominent approach in the high-level political forum, the Global Sustainable Development Report, and the creation of nexus partnerships.

In terms of process and substance, these articles illustrate that seeds of transformation do exist within the SDGs. However, there are significant limitations on these illustrated in the articles. The intergovernmental process that created the SDGs may have limited replicability in other negotiations. Inclusiveness is given rhetorical mention, but concrete efforts to deal with political inequality or to include people in the process is limited. Finally, while it proclaims an integrated, nexus approach to the various issues, the SDGs as articulated do not fully push such a vision. As we enter the 2015-2030 period where the SDGs aim to play a key role over sustainability, the key questions will reflect the political vision at the international level and will for implementation at the local and national levels. The analysis in these papers opens spaces for further interventions to improve the practices of sustainability around the world. Indeed this is the very opportunity that the SDGs have brought in. Instead of negotiating hard law involving member states and creating an international legal framework, a new global governance approach stimulated by the SDGs starts with aspirations without defining concrete implementation methods. The visions and processes embodied in the SDGs are now left for creative thinking and application in the implementation stage by an increasingly diverse set of actors.

\section{References}

Andresen, S., \& Underdal, A. (2012). We do not need more global sustainability conferences. Earth System Governance. (06/19/2012) http://www.ieg.earthsystemgovernance.org/news/2012-06-19/we-do-notneed-more-global-sustainability-conferences. Accessed September 1, 2015.

Bernstein, S., \& Cashore, B. (2012). Complex global governance and domestic policies: Four pathways of influence. International Affairs, 88(3), 585-604.

Best, J. (2014). Governing failure: Provisional expertise and the transformation of global development finance. Cambridge: Cambridge University Press.

Griggs, D., Stafford-Smith, M., Gaffney, O., Rockström, J., Ohman, M. C., Shyamsundar, P., et al. (2013). Sustainable development goals for people and planet. Nature, 495, 305-307.

Pattberg, P., \& Mert, A. (2013). The future we get might not be the future we want: Analyzing the Rio+ 20 outcomes. Global Policy, 4(3), 305-310.

Rockström, J., Steffen, W., Noone, K., Persson, Å., Chapin, F. S., Lambin, E. F., et al. (2009). A safe operating space for humanity. Nature, 461, 472-475.

Steffen, W., Richardson, K., Rockstrom, J., Cornell, S. E., Fetzer, I., Bennett, E. M., et al. (2015). Planetary boundaries: Guiding human development on a changing planet. Science, 347(6223), 730-735.

Steffen, W., \& Smith, M. S. (2013). Planetary boundaries, equity and global sustainability: Why wealthy countries could benefit from more equity. Current Opinion in Environmental Sustainability, 5(3-4), $1-6$.

UN General Assembly. (2012). The future we want. A/RES.66/288 (11 September). http://www.un.org/ga/ search/view_doc.asp?symbol=A/RES/66/288\&Lang=E. Accessed May 2, 2015.

Westley, F., Olsson, P., Folke, C., Homer-Dixon, T., Vredenburg, H., Loorbach, D., et al. (2011). Tipping toward sustainability: Emerging pathways of transformation. Ambio, 40(7), 762-780. 